\title{
PEDAGOGIA HOSPITALAR SOB A ÓTICA DOS PROFISSIONAIS: DISCUTINDO A FORMAÇÃO UNIVERSAL COMO DIREITO HUMANO
}

\author{
EVANDRO LUIZ SOARES BONFIM* \\ CRISTINA MIYUKI HASHIZUME**
}

\begin{abstract}
RESUMO
O presente trabalho traz um recorte de dissertação defendida e tem por objetivo analisar a percepção de pedagogos em relação à formação acadêmica e profissional para atuar em classe hospitalar, brinquedoteca e leitos hospitalares. O estudo também toca em aspectos como a formação continuada do pedagogo e os desafios enfrentados por eles nessa atividade. Método: o estudo é qualitativo, usando como instrumento entrevistas semiestruturadas com dezoito profissionais que atuavam em doze instituições de ensino na Grande São Paulo. Resultados: constatou-se formação inicial insuficiente no curso de Pedagogia para a atuação nesse contexto hospitalar. Ressalta-se a importância da formação para a diversidade, tanto dos alunos quanto dos cenários de atuação docente. Para que as novas gerações tenham um avançado grau de cidadania é necessário que se forme o professor para a interdisciplinaridade, bem como garantir ao aluno seu direito pleno à educação.

Palavras-chave: Pedagogia hospitalar. Classe hospitalar. Inclusão. Formação docente.
\end{abstract}

\footnotetext{
ABSTRACT

This papper presents an portion of a dissertation defended and it aims to analyze the perception of teachers about the training

* Mestre em Educação e Saúde.

** Professora Doutora do Programa de Pós-Graduação em Educação da Universidade Metodista de São Paulo.
} 
to work in hospital classes. The study also discuss about aspects such as the continuing education of the pedagogue and the challenges faced by their activities. Method: the study is qualitative, using semi-structured interviews with eighteen professionals who worked in twelve educational institutions in Greater São Paulo. Results: there was insufficient initial training in the Pedagogy course to work in this hospital context. Emphasis is placed on the importance of training for diversity, both for students and for teaching practice scenarios. For the new generations to have an advanced degree of citizenship, it is necessary to train the teacher for interdisciplinarity, as well as guaranteeing the student his full right to education.

Keywords: Hospital pedagogy. Hospital class. Inclusion. Teacher training.

\section{INTRODUÇÃO}

$\mathrm{O}$ presente artigo tem como tema a classe hospitalar como ambiente importante no atual contexto social e educacional brasileiro, como cenário da educação inserido em ambientes hospitalares, possibilitando a continuidade de escolarização de crianças e adolescentes internados por período superior a 15 dias, que têm o direito de continuar sua educação independente de sua condição de saúde e/ou adoecimento.

O Ministério da Educação, Conselho Nacional de Educação, Resolução CNE/CP n², de $1^{\circ}$ de julho de 2015 (BRASIL, 2015), considera o

Currículo como o conjunto de valores propício à produção e à socialização de significados no espaço social e que contribui para a construção da identidade sociocultural do educando, dos direitos e deveres do cidadão, do respeito ao bem comum e à democracia, às práticas educativas formais e não formais e à orientação para o trabalho. (p. 2).

No Brasil, essa modalidade teve seu início em 1950, com a classe hospitalar no Hospital Municipal Jesus, em Vila Isabel, Rio de Janeiro. Mas esse atendimento de ensino só foi reconhecido 
em 1994 pelo Ministério da Educação (MEC) como parte da Política da Educação Especial que, em 1995, integra o estatuto da Criança e do Adolescente Hospitalizado. Tal estatuto foi proposto pela Sociedade Brasileira de Pediatria e oficializado pelo Conselho Nacional dos Direitos da Criança e do Adolescente na Resolução no. 41 de outubro e 1995, que, no item 9, declara o "[d]ireito de desfrutar de alguma forma de recreação, programas de educação para a saúde, acompanhamento do currículo escolar durante sua permanência hospitalar”. (BRASIL, 1995, p. 5).

Posteriormente o estatuto foi normalizado nas Diretrizes Nacionais para Educação Especial na Educação Básica (BRASIL, 2001) e no documento Classe Hospitalar e atendimento pedagógico domiciliar: orientações e estratégias (BRASIL, 2002) e recentemente no mês de setembro de 2018, foi incluído pela Lei 13.716/2018 como Art. $4^{\circ}$-A da Lei de Diretrizes e Bases da Educação Nacional no 9394/96, que expressa:

É assegurado atendimento educacional, durante o período de internação, ao aluno da educação básica internado para tratamento de saúde em regime hospitalar ou domiciliar por tempo prolongado, conforme dispuser o Poder Público em regulamento, na esfera de sua competência federativa. (BRASIL, 2018).

Trata-se de um grande avanço, pois a Classe Hospitalar deixa de ser uma recomendação e passa a ser uma modalidade obrigatória de ensino, que irá movimentar o Estado por meio das secretarias de educação estaduais ou municipais, a implementar o atendimento em todo o território nacional. Nesse aspecto, o presente projeto se mostra como importante possibilidade de refletirmos sobre os desafios para a Educação e para a Psicologia, no que diz respeito a todo o complexo processo de adaptação das crianças/estudantes no hospital.

Soma-se a isso o direito que toda criança em idade escolar tem de ter acesso universalmente à educação para sua formação cidadã. Nesse sentido, entendemos que a classe hospitalar se refere à educação inclusiva, tendo em vista tais crianças se 
encontrarem numa situação peculiar de aprendizado, que demanda atendimento especializado por parte do docente. Além disso, o tema aborda uma discussão sobre Direitos Humanos e também é transversal.

A atuação do pedagogo em ambientes escolares não tradicionais das escolas regulares vem se ampliando para além de se restringir somente à educação formal e sistemática. Nesse sentido, a prática pedagógica deve atuar no engendramento da subjetividade de cada criança/adolescente hospitalizado, levando-os a compreender a sua relação com as demais pessoas e com a própria situação de adoecimento, avançando na compreensão do papel da educação em ensinar apenas em ambientes educacionais tradicionais.

O presente artigo tem por objetivo: analisar a percepção de pedagogos em relação à formação acadêmica e profissional para atuar em classe hospitalar, brinquedoteca e leitos hospitalares. O estudo também tocou em aspectos como a formação continuada do pedagogo e os desafios em in-exclusão enfrentados por eles.

\section{MÉTODO}

Após avaliação de instituições que apresentavam classes hospitalares na cidade de São Paulo, foram realizadas visitas aos hospitais, num total de doze instituições (dez hospitais e duas ONGS). A pesquisa foi submetida ao Comitê de Ética da universidade, recebendo sua aprovação. Foram entrevistados 18 pedagogos atuantes nessas classes hospitalares, a partir de roteiro de perguntas semiestruturadas.

Para alcançar tal objetivo utilizou-se a análise de conteúdo na modalidade temática. A análise de conteúdo permite descobrir o que está por trás dos conteúdos manifestos, indo além das aparências do que está sendo comunicado. A análise de conteúdo agrega um conjunto de técnicas separando os temas segundo as características dos conteúdos, como a análise de avaliação ou análise representacional, a análise de expressão, 
a análise de enunciação e a análise temática. (MINAYO, DESLANDES e GOMES, 2010).A modalidade análise temática foi utilizada neste estudo, tendo como tema o juízo central, que pode ser representado por uma palavra, uma frase ou um resumo. As falas das entrevistas foram transcritas na íntegra e organizadas em texto corrido para cada participante, segundo a metodologia de Minayo et al (2010) para a análise de conteúdo, num processo que incluiu três etapas. Numa primeira etapa foi realizada a leitura do material, buscando de um lado ter uma visão de conjunto e, de outro, apreender suas particularidades. Numa segunda etapa realizou-se a exploração do material em que foi feita a análise propriamente dita, sendo de fundamental importância ir além das falas e dos fatos, caminhando na direção do que estava explícito para o implícito. Na etapa final foi elaborada uma síntese interpretativa, articulando os objetivos do estudo, a base teórica adotada e os dados empíricos.

A partir da leitura e releitura das falas com a finalidade da impregnação dos sentidos presentes nos textos, definiu-se os núcleos direcionadores da análise e os dados foram inseridos em um quadro sinóptico construído para a organização das Unidades de Contexto (UC) e Unidades de Registro (UR) que possibilitaram a categorização e subcategorização dos conteúdos expressos. A unidade de registro é a menor parte do conteúdo e pode incluir a palavra, o tema, o personagem e/ou o item, por exemplo. Segundo Moraes (1999), a unidade de contexto é a parte mais ampla do conteúdo, ou seja, o contexto do qual faz parte a mensagem que será analisada.

\section{RESULTADOS E DISCUSSÃO}

Após a leitura, releitura e a busca de significados do material coletado com as entrevistas, os dados foram categorizados e organizados em quadro sinópticos com os núcleos direcionadores, as categorias e subcategorias originadas da análise das falas dos entrevistados. Sobre a ética desta pesquisa, destaca-se 
que a identidade dos participantes foi preservada, e os mesmo foram identificados como entrevistados (E) seguido de numeral em sequência (E1, E2, E3 ... até E8). As falas foram analisadas a partir de duas Unidades Direcionadoras (UR's):

a) Formação do pedagogo para atuar em classe, brinquedoteca e leito hospitalares e b) sugestões para o aprimoramento das práticas pedagógicas na classe hospitalar, brinquedoteca e leito hospitalar.

Quadro 1. Apresenta as categorias e subcategorias do primeiro núcleo direcionador Formação do pedagogo para atuar em classe, brinquedoteca e leito hospitalares

\begin{tabular}{|c|c|}
\hline CATEGORIAS & SUBCATEGORIAS \\
\hline $\begin{array}{l}1 \text { - Preparo para atuar na } \\
\text { classe hospitalar, leito e } \\
\text { brinquedoteca }\end{array}$ & $\begin{array}{l}\text { 1a. Formação inicial e continuada } \\
\text { 1b - Sensibilidade do profissional para atuar } \\
\text { contexto hospitalar } \\
\text { 1c. Conhecimento do estado de saúde do } \\
\text { estudante/paciente } \\
\text { 1d. Ética no contexto hospitalar }\end{array}$ \\
\hline 2- Contexto da Atuação & $\begin{array}{l}\text { 2a. Trabalho em equipe } \\
\text { 2b. O ambiente de trabalho } \\
\text { 2c. Experiência profissional }\end{array}$ \\
\hline $\begin{array}{l}3 \text { - Papel do Pedagogo no } \\
\text { contexto hospitalar }\end{array}$ & $\begin{array}{l}\text { 3a. Atribuições do Pedagogo hospitalar } \\
\text { 3b. Competências e habilidades } \\
\text { 3c. Inclusão da criança e do adolescente }\end{array}$ \\
\hline $\begin{array}{l}4 \text { - Desafios da Pedagogia } \\
\text { Hospitalar }\end{array}$ & $\begin{array}{l}\text { 4a. Percepções dos desafios } \\
\text { 4b. Direito à Continuidade de escolarização em } \\
\text { contexto hospitalar } \\
\text { 4c. Humanização no cuidado }\end{array}$ \\
\hline $\begin{array}{l}5 \text { - Infraestrutura dos } \\
\text { ambientes educacionais } \\
\text { hospitalares }\end{array}$ & $\begin{array}{l}\text { 5a. Recursos materiais } \\
\text { 5b. Brinquedoteca como setor de humanização } \\
\text { 5c- Infraestrutura acadêmica } \\
\text { 5d. Participação da Família }\end{array}$ \\
\hline
\end{tabular}

(Fonte: os autores, 2016). 
Do primeiro núcleo direcionador emergiram cinco categorias e 19 subcategorias. Por se tratarem de muitos aspectos, apresentaremos as categorias, e dentro de cada uma delas, discorreremos sobre as subcategorias brevemente.

A primeira categoria que emergiu foi o Preparo do pedagogo para atuar na classe hospitalar, leito e brinquedoteca, com quatro subcategorias, que estão apresentadas a seguir.

A primeira se refere à formação inicial e continuada, já que nem todos os docentes tinham perfil para trabalhar em hospital, sendo necessário treinamento consistente que prepare os profissionais para atuarem no contexto hospitalar. Conhecimentos peculiares à patologia do aluno também eram necessários para se respeitar a rotina institucional. Além de um treinamento inicial, também era necessária capacitação contínua, pois o hospital é um ambiente inusitado e heterodoxo, que recebe pacientes diferentes a cada dia e traz mudanças no trabalho dos professores (CRUZ; ARAÚJO, 2014).

Se observarmos que a Pedagogia Hospitalar deve atuar como uma extensão da escola, o pedagogo em si deve estar preparado para qualquer situação, isto é, na própria escola ele tem que estar apto para contornar quaisquer dificuldades físicas e/ou emocionais de seus alunos. (E1-UR12) ${ }^{1}$.

[...] Existem várias e várias situações com as quais o pedagogo vai se deparar e não é preparado para elas. Por isso, nos cursos de Pedagogia deveria haver a ampliação dos conteúdos ligados às deficiências físicas e mentais, saúde da criança, sem falar do estágio obrigatório em hospitais. (E1-UR13).

Cruz e Araújo (2014) salientam que o docente precisa conhecer as patologias mais frequentes no hospital, principalmente aquelas que acometem seus estudantes, ter noções terapêuticas

Este depoimento, assim como os outros com estas indicações, foi obtido nas entrevistas para a pesquisa, realizadas em setembro de 2016, em São Paulo, tendo sido posteriormente transcritas e autorizadas pelo entrevistado. 
que fazem parte da rotina na enfermaria, as formas de tratamento, medicação usada e sua influência no indivíduo, devendo conhecer as condições de saúde de seus estudantes, suas potencialidades e possibilidades, o que ajuda na compreensão da hospitalização como um todo. O docente deve "ouvir as histórias de vida dos alunos, para poder compreendê-los melhor e ajudá-los a superar e ressignificar sua internação e sua doença” (p. 27).

[...] o profissional pedagogo deve manter-se atualizado, pois os adoecidos que irá atender estão emocionalmente enfraquecidos... e requerem um cuidado diferenciado. (E1- UR5).

Os conhecimentos sobre saúde são importantes para a boa formação desse profissional. (E2 - UR43).

Os entrevistados relataram que o currículo da Pedagogia não foi suficiente para a sua atuação, sendo necessários investimentos educacionais por parte do próprio profissional, tendo sido raros os casos em que se citam a participação em programas de educação continuada oferecida por parceria entre as secretarias de educação e hospitais.

Em que pese o fato de no Brasil ainda não existir curso específico de Pedagogia Hospitalar em nível de graduação, são oferecidos componentes curriculares relativos à temática da ação pedagógica em espaços não regulares, sendo o contexto hospitalar um desses espaços. Em nível de graduação os cursos de Educação Especial têm contemplado a especificidade das classes hospitalares, sendo relegada, portanto, a uma formação em nível de pós-graduação.

Uma das experiências encontradas na literatura foi descrita por Loss (2015), numa disciplina ofertada no curso de Pedagogia da Universidade Federal da Fronteira do Sul, instituição esta que reconhece ser a Pedagogia Hospitalar "um processo alternativo de educação, pois, levanta parâmetros para o atendimento de necessidades especiais transitórias do educando, em ambiente hospitalar e/ou domiciliar" (LOSS, 2015, p. 367).Ainda, Zom- 
bini et al. (2012) ressaltam ser a prática pedagógica em hospitais uma possibilidade de aperfeiçoamento humano como um todo, contribuindo assim para o desenvolvimento infantil e ampliando sua experiência de vida na medida que desperta a valorização de si própria, liberação de potenciais na criança, superando os momentos de tensão que a hospitalização impõe.

Rodrigues (2012) discute a visão fragmentada e recorrente de pesquisadores em relação às teorias pedagógicas, razão pela qual os profissionais de educação têm dificuldade em justificar suas ações pedagógicas, e nesse sentido é fato que "forma-se o professor muito mais falando do metier do ensino do que oportunizando a vivência da prática pedagógica" (RODRIGUES, 2012, p.13).

No que se refere à subcategoria sensibilidade do profissional para atuar contexto hospitalar, não se espera formar ou tornar um profissional sensível, mas, sim, que a pessoa existente nesse profissional tenha sensibilidade quando em ações que envolvem as relações humanas em diferentes circunstâncias. Nesse sentido, a Resolução $n^{\circ} 2$, de $1^{\circ}$ de julho de 2015, no Artigo $7^{\circ}$, aborda a questão das habilidades e competências que devem ser desenvolvidas, quando explica que na formação inicial e continuada, o aluno deverá possuir um repertório de informações e habilidades composto pela pluralidade de conhecimentos teóricos e práticos, resultado do projeto pedagógico e do percurso formativo (2015), o que veremos nos excertos das entrevistas:

Tenho uma palavra para começar a descrever o dia a dia com essas crianças... Esperança. [...] procuro dar a eles (crianças e adolescentes internados), além do conteúdo programático das suas escolas, a esperança e a alegria. (E1-UR17).

Quando falo lazer, quero dizer sobre o lúdico [...], utilizando das diversas formas de brincadeiras para ensinar, aliviando também a pressão emocional que o adoecido sofre por estar em um ambiente hostil aos seus olhos. (E1-UR16). 
A atuação de cada professor hospitalar é muito diferente da atuação de um professor da escola regular, sendo necessário, numa "visão ampliada", dedicar atenção ao estudante/paciente, respeitando suas peculiaridades e necessidades, aspecto que apenas uma formação inicial não consegue garantir neste contexto.

O pedagogo ou professor precisa saber ouvir, mais do que falar, na maioria dos casos. Freire (1996) enfatiza que "escutar é obviamente algo que vai mais além da possibilidade auditiva [...] Escutar, no sentido aqui discutido, significa a disponibilidade permanente por parte do sujeito que escuta para a abertura à fala e diferenças". (1996, p. 135), devendo o docente hospitalar transpor o contexto rotineiro e construir novas práticas para o cenário hospitalar, envolvendo todos os atores.

A subcategoria conhecimento do estado de saúde das crianças que recebem atendimento pedagógico hospitalar baseia-se no que Freire (1996), chama de "o bom senso não me diz o que é, mas deixa claro que há algo que precisa ser sabido" (p. 70), referindo-se ao histórico e ao aprendido pela criança. Também entendemos, a partir das entrevistas, que a vida dos alunos toma outros sentidos, considerando aspectos da cultura peculiar do aluno e suas inter-relações estabelecidas entre família, escola, comunidade, religião, entre outros.

A Lei 6.514 de 22/12/1977 prevê que serviços de saúde ofereçam assessoramento permanente ao professor, bem como insira-o na equipe de saúde que coordena o projeto terapêutico individual. Ao professor é necessário o acesso aos prontuários dos usuários, ações e serviços de saúde sob atendimento pedagógico, seja para obter informações, seja para prestá-las do ponto de vista de sua intervenção e avaliação educacional. Vejamos os relatos:

Existe aqueles que precisam constantemente do cilindro de oxigênio e, às vezes, não podem locomover-se muito, dessa feita... ficam mais... isolados. Trabalho com todos de maneira que essa criança que está um pouco mais distante seja incluída, isto é, usando de brincadeiras integro todos em um mesmo conjunto. (E1-UR18). 
Conhecer a linguagem técnica e ter conhecimento sobre as diversas patologias. (E2 - UR45).

A subcategoria ética no contexto hospitalar refere-se ao que Rodrigues (2012) apresenta como uma construção de atitude ética, pedagógica do docente, considerando-se as contradições e os compromissos profissionais. Tais fatos se tratam de oportunidades de refletir sobre as práticas docentes, seus motivos e intencionalidades.

Respeitar o direito de privacidade das informações prestadas pelo próprio cliente e da equipe de funcionários do hospital [...] levar em consideração a confiança que o cliente deposita nas pessoas com quem se relaciona. (E2- UR46).

[...] acima de tudo essa questão é... burocrática... como posso te falar... muitas vezes a pessoa não está nem aí ... comenta sobre os casos...você fala 'meu Deus do céu', o que é isso!!! (E6 - UR128).

Nesse sentido, respeitar o sigilo e tratar com cuidado as informações relativas à doença da criança trata-se de atitude ética fundamental. No contexto hospitalar, significa respeitar as individualidades de todos os envolvidos no processo de ensino e aprendizagem em classe hospitalar ou fora dela, bem como a individualidade dos profissionais de saúde e, principalmente, dos que compõem a equipe multidisciplinar no atendimento aos alunos pacientes. Ao se respeitar essas históricas, o trabalho em equipe certamente será de qualidade.

A segunda categoria, contexto da Atuação, contem três subcategorias. Nesta categoria surgiram falas que nos remetem às discussões sobre: o trabalho em equipe, o ambiente de trabalho no contexto hospitalar e a experiência profissional adquirida nesta atuação, em complementação à formação inicial e continuada.

No que se refere à subcategoria trabalho em equipe, corroboramos a discussão de Zombini (2012), que apresenta que a organização de grupos de discussão de problemas do dia a dia 
hospitalar, participação de profissionais da equipe de saúde e dos usuários, além de práticas que amenizam efeitos negativos-físicos, emocionais e sociais da internação e garantem o respeito e a cidadania dos indivíduos, evidenciado nas entrevistas:

Em nossa equipe, além de pedagogos, temos psicólogos e assistentes sociais, todos formando uma parceria para o atendimento dessas crianças e adolescentes em situação de adoecimento e impossibilitados de frequentar a escola regular. (E1 - UR27).

[...] eu acho que ... se você não sabe trabalhar em equipe, você também não consegue trabalhar! Eu percebo isso em algumas professoras, porque vem com um olhar de escola... e a gente não... aqui não é escola ...aqui é um hospital! (E4-UR74).

Estas iniciativas são importantes quanto aos sentimentos que se manifestam em pacientes em situação de internação, como: sentimentos negativos em relação a si e em relação ao hospital, angústias, tristezas, lembranças de perdas de entes queridos e o medo da morte.

O trabalho em equipe também pode se relacionar a ações de recreação em ambientes hospitalares, desenvolvidos pelas equipes de saúde, educação e voluntários.

Zombini (2012) destaca iniciativas de hospitais que atendem crianças e adolescentes em situação de internação e as atividades oferecidas ao perfil etário e patológico dessa clientela. Para o autor, além das atividades humanizadoras, outros esforços vêm sendo empreendidos para a criação de ambientes destinados ao atendimento pedagógico-educacional, que permitem a continuidade do desenvolvimento cognitivo e educacional dos estudantes/ pacientes durante o período de hospitalização.

Os cenários de atuação permitiram conhecer o papel do pedagogo e sua importância como membro de equipe interdisciplinar. Há que se distinguir que existem projetos, propostas e atividades desenvolvidas nos hospitais que nem sempre atendem ao objetivo da Pedagogia Hospitalar, qual seja, o de garantir a 
continuidade de escolarização de crianças em situação de internação de longa permanência, cabendo ao pedagogo mediar a relação entre escola regular e estudante/paciente.

A subcategoria "ambiente de trabalho no contexto hospitalar” ressalta emoções, positiva e negativamente, pode-se imaginar o que este ambiente significa para crianças e adolescentes internados e seus acompanhantes.

... o ambiente já favorece ... é sair de dentro de um quarto pra uma sala que tem brinquedo, que tem jogos, que tem uma professora. Imagina tem uma professora ali pra me atender, para, de repente, me dar uma aula particular né?... para as mães também ... porque algumas mães ficam junto com eles por meses ...(E3 - UR95).

Aqui, onde você está, especificamente no $2^{\circ}$ andar, aqui os médicos são ... urologia e nefrologia, aqui são os (casos) mais crônicos... aqui tem a diálise, hemodiálise ... alguns estão na fila pro transplante. Aqui é doença crônica ... e no $3^{\circ}$ é cirurgia ... é ... hematologia! A gente tem muitas crianças com anemia falciforme e cirurgias, no geral, né? até... reparações ... cirurgias plásticas, também são feitas. É um setor mais de cirurgia e de hematologia. (E3 - UR96).

De acordo com Dahdah et al (2013), o hospital

[...] é uma invenção moderna que ao longo do tempo sofreu e sofre muitas transformações. No entanto, mesmo com as mudanças no caráter e objetivos da instituição hospitalar, esse espaço permaneceu com característica de disciplinador (a disciplina dos corpos, comportamentos e pensamentos) e caritativo [...] para que essa disciplinarização se efetive, o doente é "infantilizado", tornando-o submisso e melhor controlado, e a organização dos cuidados é feita através da racionalização de serviços, da organização do espaço, do controle dos comportamentos e das restrições das atividades. (p. 400).

Ressalta-se, a partir da citação de Dahdah et al, a importância dos profissionais de educação em contexto hospitalar no sentido de romper com o processo "infantilizador" decorrente da internação de seu aluno. O desenvolvimento de atividades que ultrapassem as limitações advindas da hospitalização favo- 
recem momentos de prazer e construção de saberes repletos de sentidos para cada um dos alunos pacientes.

A subcategoria experiência profissional em contexto hospitalar, baseado no que Freire (1996, p. 58) afirma, de que "[n]inguém nasce educador ou marcado para ser educador. A gente se faz educador, a gente se forma, como educador, permanentemente, na prática e na reflexão da prática”.

[A] tuo como autônomo; constituí empresa (ONG) para ajudar crianças com dificuldades, atuo com crianças soropositivas e não parei mais. (E2- UR31).

E no caso da classe hospitalar [...] a gente tem que fazer um projeto... e levar esse projeto até uma diretoria de ensino. Então aí você tem que se envolver mais mesmo nessa área... (E3 - UR62).

O pedagogo do contexto hospitalar pode ser contratado diretamente pelo hospital, quando este não tem convênio estabelecido com as diretorias e secretarias de educação. No caso dos hospitais públicos, municipais e estaduais, o pedagogo é encaminhado para o hospital conforme espaço e número de crianças e adolescentes que estejam internados e devidamente matriculados nas redes de ensino.

Caso a criança ou adolescente não tenha vínculo com a escola regular, caberá ao pedagogo juntamente com a família e equipe multidisciplinar dar providências para que o vínculo com a escola se estabeleça. A permanência, no hospital, porém, não deve representar rompimento do vínculo com a escola e a perda do direito à escolarização. Além da garantia do contato com o saber, as classes hospitalares estimula o processo cognitivo e de desenvolvimento, favorecendo relações interpessoais (ZOMBINI et al, 2012).

A terceira categoria que emergiu neste primeiro núcleo direcionador foi o "Papel do Pedagogo no contexto hospitalar".

Nesta categoria foi possível analisar as atribuições do pedagogo hospitalar, as competências e habilidades necessárias 
ou desenvolvidas no decorrer do exercício profissional, além da ética no contexto hospitalar Os conhecimentos adquiridos por estes profissionais sobre o ECA, LBD e humanização na saúde foram explicitados durante as entrevistas.

\section{A subcategoria Atribuições do pedagogo hospitalar} destaca aspectos relacionados à necessidade do vínculo com a escola regular e a necessidade da organização e atualização do prontuário pedagógico.

Só o fato de dar continuidade ao aprendizado escolar da criança já é o ponto principal do contexto da Pedagogia Hospitalar. Outros pontos estão relacionados a diminuir ao máximo os efeitos negativos do impacto da doença e do ambiente do hospital. (E1-UR23).

Devido à minha formação na área da Pedagogia, somada às técnicas da enfermagem, o cuidar do indivíduo para mim é fundamental como recurso para desviar o paciente do foco no problema - a doença. (E2 - UR35).

A atuação profissional do pedagogo ou professor em contexto hospitalar, deve, portanto, considerar quais são as suas atribuições neste contexto, para que se possa compreender quais as experiências desejadas. Silva et al (2015, p. 49), esclarecem que tal prática ajuda a amenizar o sofrimento dessas crianças, que sofrem transtornos emocionais os mais diversos.

Durante as entrevistas esse posicionamento fica evidente as atribuições do pedagogo hospitalar estão relacionadas à função e à responsabilidade ligadas à profissão no contexto hospitalar, corroborando Loss (2015), segundo o qual o pedagogo deve primar pelos deveres de educar, num um processo dinâmico, histórico e de transformação, abrangendo as dimensões: social, cultural, política, econômica e ética.

Nesse sentido, no contexto do hospital, as formas de abordagem e as estratégias usadas pelo docente são diferentes. Além do mais, existe ainda o compromisso em atender as ex- 
pectativas dispostas nos relatos dos nossos entrevistados na subcategoria abaixo.

Em relação à necessidade do vínculo do pedagogo com a escola regular, têm-se as seguintes reflexões:

[...] quando a escola se mostra presente é muito bom! Mas não é sempre que a gente tem esse respaldo da escola ... a gente às vezes tem que ficar atrás. (E3 - UR89).

Se tivesse uma parceria da escola com o hospital ajudaria bastante o desenvolvimento da criança, pois a criança não deve parar o desenvolvimento cognitivo dela, ela sempre tem que estar em andamento, sempre aperfeiçoando. O que me entristece é que as famílias não participam disso. Então elas ali com as crianças dentro do hospital e o que é mais importante para elas é cuidar da criança e não do que (elas devem) estudar. (E5 - UR118).

Conforme preconiza o MEC (BRASIL, 2002, p. 19) nas competências das secretarias de educação, que devem garantir a melhoria da inclusão escolar através da educação inclusiva, faz-se mister ter acesso e conhecer a história do estudante por meio dos prontuários pedagógicos, tanto aos gestores como aos docentes:

(...) uma pessoa que não tem essa preocupação, não tem como trabalhar aqui, como aconteceu anteriormente, há seis anos. Acho interessante isso ser uma regra já estabelecida! A gente ter esse acesso! Um exemplo: 'olha... cheguei agora às treze horas, hoje ela não se sentiu bem, precisou ser medicada com tal medicamento'. Antes de (o professor) começar a atuar mesmo, saber qual é o histórico, o que essa criança tem, por que que ela está internada, qual é a gravidade, mesmo que envolve isso! Isso é importante para o meu trabalho, para eu conseguir desenvolver meu trabalho melhor. (E6-UR139).

Em períodos longos de internação foi estabelecida uma parceria com a escola do estudante/paciente, na qual o professor da escola regular auxiliava a família e o pedagogo do hospital na continuidade dos estudos. Todos os procedimentos realizados no hospital são registrados no prontuário, de forma que todos da 
equipe interdisciplinar possam acompanhar o desenvolvimento integral do paciente.

A subcategoria Competências e Habilidades trata de conceitos obtidos durante a formação inicial do docente para adaptar atividades pedagógicas em contexto hospitalar, uma vez que o currículo de Pedagogia contempla componentes curriculares da Educação Especial, que trata, entre outros temas, de estratégias e recursos didáticos para o atendimento de pessoas com necessidades educacionais especiais. Assim, requer do docente criatividade para adaptação de recursos e materiais em contexto hospitalar.

[...] daí, o papel fundamental do pedagogo, enquanto ser humano, intervir, promover a interação do cliente com o meio, com a família e com o próprio quadro de funcionários do setor hospitalar. (E2-UR60).

[...] quando a gente fala de competências e habilidades necessárias é que [o professor] precisa de um verdadeiro saber interdisciplinar". (E4 - UR21).

Sobre as competência e habilidades dos profissionais de educação que atuam em contexto hospitalar, esses devem reunir saberes que permitam a construção de planejamento adequado ao contexto, possibilitando-lhes criar estratégias e adaptar todos os recursos para trabalhar os conteúdos que são propostos pela escola regular com ludicidade.

A construção do conhecimento a partir do lúdico requer do pedagogo ou professor hospitalar, perfil, olhar e atitudes muito diferenciados. O lúdico não significa apenas brincar para aprender e ensinar, mas permitir construir saberes e avaliar os resultados. Obviamente, nenhum professor sozinho será capaz de atender a todas as necessidades individuais dos seus alunos.

Trabalhar com o lúdico, portanto, é possibilitar que as crianças e adolescentes se percebam no mundo, ultrapassem os limites impostos pela hospitalização a partir da imaginação e do que recursos lúdicos permitem. Afinal, como diz Freire (1996), 
a presença no mundo não é de quem a ele se adapta, mas a de quem nele se insere como protagonista da história, criando, transformando e construindo como sujeito a sua práxis. O pedagogo e o professor hospitalar com este expediente podem mantê-los ativos e fortes diante da doença, o que, acredita-se, interfere no quadro de saúde dos estudantes/pacientes positivamente.

No processo formativo inicial do pedagogo não há aprofundamento de estudos para a atuação profissional em contexto hospitalar, e sim, orientações e experiências para atuação em diferentes contextos. Porém, atividades lúdicas são tratadas no processo formativo do pedagogo na perspectiva da Educação Infantil e séries iniciais, que modo que não se trata de obstáculo ao pedagogo adaptar atividades lúdicas a serem trabalhadas no contexto hospitalar. Como Rubio (2012) defende, a adaptação à especificidade hospitalar deve uma nova consciência em que a sensação, o sentimento, a integração e a razão cultural valorizem o indivíduo num processo proativo e construtivo-formador (RUBIO, 2012, p.10).

A subcategoria inclusão da criança e do adolescente a Segundo um entrevistado:

[...] existe uma exclusão, um negar desse conhecimento educacional de fato para crianças que estão hospitalizadas. Eu acompanhei muitos casos de crianças que são hospitalizadas [...] dependendo da situação três, seis meses ou um ano de internação que ficam fora da escola! [...] são crianças que nunca tiveram acesso à escola e nem terão acesso a ela, não conhecem, lhes foram negados até o dia de hoje os saberes necessários dento de uma escola! Então eu estou tentando trazer esses conhecimentos para facilitar o acesso deles à educação. (E6 - UR153).

O tema inclusão/exclusão nas entrevistas remete a discussões por questões étnicas, religiosas, sociais, econômicas, políticas e de classe social e acessibilidade. No que diz respeito ao atendimento escolar em classes hospitalares, o Ministério da Educação - Secretaria de Educação Especial (BRASIL, 2002), orienta que: 
$\mathrm{Na}$ impossibilidade de frequência à escola, durante o período sob tratamento de saúde ou de assistência psicossocial, as pessoas necessitam de formas alternativas de organização e oferta de ensino de modo a cumprir com os direitos à educação e à saúde, tal como definidos na Lei e demandados pelo direito à vida em sociedade. Esta atenção também diz respeito ao paradigma de inclusão e contribui para com a humanização da assistência hospitalar. (p.11).

A educação no contexto hospitalar não deve excluir nenhuma criança ou adolescente internado, mas sim, oferecer atividades que garantam a continuidade de escolarização. Porém, a legislação prevê, dubiamente, uma ação que se contrasta com o cenário manifesto, em que famílias não têm acesso ao direito por falta de informação, ou através da banalização do direito à inclusão, simplificando-a a uma inclusão física e de acessibilidade. A despeito dessa visão mais simplista do processo, precisamos que a inclusão escolar nos hospitais possa emancipar o aluno, promovendo a reflexão, discussão e dando-lhe autonomia para pensar sobre o mundo.

Como quarta categoria do primeiro núcleo direcionador tem-se: Desafios da Pedagogia Hospitalar.

A subcategoria percepções dos desafios a serem enfrentados referiu-se ao que a literatura apresenta como questões relativas à escolarização da criança com doença crônica (COLLET E HOLANDA, 2011), sendo inúmeras as dificuldades enfrentadas quando se fala em. Exemplos delas são: a falta de informação na escola sobre a doença, a indiferença por parte dos hospitais com a situação acadêmica dos seus pacientes, a falta de comunicação entre escola e hospital, o desleixo das direções escolares que não se empenham em melhorar a integração do seu aluno doente.

Um dos papéis que considero fundamentais na Pedagogia hospitalar é o de transformar o ambiente hospitalar em um ambiente mais agradável. (E2 - UR48).

O grande desafio hoje realmente para uma Pedagogia com princípios (metas) e avaliações, por mais que sejam diferenciadas da Pedagogia escolar, mas que sejam próprias, é a Pedagogia Hospitalar. (E6 - UR141). 
Entre os impasses se destacam também a dificuldade de professoras em trabalhar com o aluno hospitalizado, a impotência da criança diante de tantos obstáculos e a falta de compromisso de gestores com o desenvolvimento e implementação de políticas públicas efetivas que garantam o direito de continuidade do processo de escolarização de crianças e adolescentes hospitalizados.

Tais desafios engendram esforços para a legitimação da Pedagogia Hospitalar: além das dificuldades relativas à falta de aproximação entre os setores de saúde e educação, também foi identificada carência de informações à sociedade sobre a importância de se garantir a continuidade de escolarização de crianças e adolescentes em situação de internação.

Collet e Holanda (2011) problematizam dois setores extremamente fragilizados: Saúde e Educação e seus impactos para o trabalho nas classes hospitalares. Tal fato requer que profissionais de diferentes áreas realizem da intersetorialidade uma ferramenta de trabalho a fim de visualizar a criança integralmente, envolvendo: gestores públicos, hospital, família e escola.

Por iniciativa própria, instituições de ensino superior investem na oferta de cursos em diferentes modalidades para formação de profissionais com vistas a atuar em Pedagogia Hospitalar; outras instituições optam por oferecer estágios. Há ainda situações em que estudantes se voluntariam nos projetos construídos por ONGs para atendimento de escolares em situação de internação.

A Pedagogia Hospitalar se mantém apoiada na legislação da Educação Especial.

Zombini, et al. (2012) destacam que

percebe-se um despreparo tanto por parte dos profissionais da saúde quanto por parte dos profissionais da educação para o desenvolvimento de ações que devem ser complementares. Também há dificuldade para o estabelecimento de relações interpessoais que poderiam favorecer as condutas ante as crianças e os jovens hospitalizados. (p. 74). 
Diante das considerações de Collet e Holanda (2011) e Zombini (2012), temos que ressaltar que há grandes esforços para a melhoria do atendimento de escolares/ pacientes, para aproximação de equipes pedagógicas e de saúde para qualidade no atendimento das crianças e adolescentes, tanto nos aspectos de saúde quanto de educação.

É oportuno ressaltar que a Pedagogia Hospitalar é um tema ainda pouco discutido no mundo acadêmico, tendo início no século XXI, mas o atendimento em classe hospitalar não é recente e tudo que se tem feito desde sua origem contribui em muito para estudos e pesquisas que trazem os caminhos para melhorar e ampliar este atendimento.

A subcategoria Direito à Continuidade de escolarização em contexto hospitalar, aponta as seguintes falas:

[...] a legislação consiste em oferecer atendimento escolar às crianças e adolescentes em hospitais, quando, pelo motivo de uma internação, são impedidas de frequentar classes regulares. Com o intuito de que não haja interrupção nos processos de aprendizagem, portanto é um auxílio prestado aos enfermos que estão em processo de alfabetização". ( E2 - UR49).

[...] contempla porque se você procurar e esmiuçar essa legislação você vai achar um bracinho ali na LDB que fala um pouquinho, é muito bacana isso. (E4 - UR97).

O hospital não é o único ambiente que difere da escola regular, mas que necessita dar atendimento escolar para crianças e adolescentes internados por curtos ou longos períodos, por doenças crônicas ou tratamentos prolongados por enfermidades diversas.

Cruz e Araújo (2014) ressaltam que a continuação do processo de educação escolarizada estimula a sua permanência após a alta, o que minimiza o risco de um possível fracasso escolar que pode ocasionar perdas significativas para a vida acadêmica dos sujeitos. Trata-se, ainda, de um auxílio significativo na redução do tempo de internação e do estresse causado pela doença, 
pelo local onde está inserido e pelo tratamento recebido, além de manter o vínculo do paciente com o mundo externo, atendendo às suas necessidades intelectuais.

A escolarização hospitalizada é um direito de crianças e adolescentes em situação de internação. Em que pese o fato de o número de instituições hospitalares que oferecem este atendimento ser insuficiente, verificou-se que na maioria dos casos os esforços para o cumprimento da lei existem. Cruz et al (2014, p. 28) reconhecem que

[o] hospital tem se configurado como um ambiente propício à assistência educacional. Embora pareça um local improvável e inusitado para o processo de ensino-aprendizagem, ele tem se mostrado um campo fértil e cheio de possibilidades para que a educação aconteça.

Mas é preciso que o pedagogo e/ou professores que atuam em contexto hospitalar tenham perfil adequado para a atuação neste local. O perfil adequado possibilitará o trabalho diferenciado, ao mesmo tempo em que favorecerá e/ou contribuirá no processo de recuperação do aluno-paciente.

A subcategoria humanização no cuidado refere-se a um pressuposto do SUS, que requer um diálogo mais ampliado com a comunidade leiga, entendendo que esta detém um conhecimento importante na construção do tratamento e reabilitação da saúde do internado.

Humanização - no hospital em que eu trabalho falam em humanização, mas eles não têm a prática. Alguns falam e outros não querem nem saber. Existe uma relação entre humanização com a parte da pedagogia dentro do hospital, onde você está lidando com crianças. Ter um tratamento humanizado também é um direito.(E5 - UR110).

A brinquedoteca faz parte do setor de humanização do hospital sob a responsabilidade de um funcionário da instituição que desenvolve a função de brinquedista. As ações da brinquedoteca são integradas às da escola hospitalar, garantindo aos infantes da 
Educação Infantil um espaço para o desenvolvimento de suas potencialidades. Nesse sentido, o

brinquedista, responsável pelas relações relativas aos processos de ensino e aprendizagem das crianças e adolescentes, se utiliza de brinquedos na aprendizagem social e cognitiva, mediando a relação criança/brinquedo (COSTA, MICAELY \& CARVALHO,2016)

A quinta categoria que emergiu no primeiro núcleo direcionador: Infraestrutura dos ambientes educacionais hospitalares.

A subcategoria recursos materiais apresentou as seguintes falas:

Aqui no hospital temos duas salas de brinquedoteca, a primeira fica no $5^{\circ}$ andar e a segunda, no $6^{\circ}$ andar. (E7 - UR164);

Como recurso material temos: 1 mesa de estudos com 3 cadeiras com rodinhas; 2 armários de duas portas; 1 TV HD LED LDC; 1 mesa octogonal com 8 cadeiras; 4 pufes com formato de dados coloridos; livros infantis diversos, revistas e gibis; 1 videogame Vbox; 1 rinoceronte de plástico, do tipo baú, porta-brinquedos, brinquedos diversos dirigidos a várias idades; 1 suporte de parede contendo álcool gel. (E7 - UR165).

Tais excertos nos remetem ao que a legislação orienta:

Providenciar em parceria com os serviços de saúde e de assistência social, mobiliário e/ou equipamentos adaptados de acordo com as necessidades do educando, como: cama especial, cadeira e mesa adaptadas, cadeira de rodas, eliminação de barreiras para favorecer o acesso a outros ambientes da casa e ao espaço externo. (BRASIL, 2002, p.17).

Fica subentendido que a aquisição de outros materiais, como, por exemplo, livros infantis e infanto-juvenis, jogos e aparelhos eletrônicos que possibilitem o acesso a informações e brincadeiras também fazem parte desta ação. Nessa perspectiva, Esteves et al (2014) explicam que deve haver informação sobre a 
existência de sinalização clara e acessível; a criação de áreas diferenciadas de jogo, descanso e tratamentos; a implementação de regras que permitam o controlo, pela família, das rotinas, atividades e a organização do seu próprio espaço, são exemplos de algumas destas medidas. Não implicando, necessariamente, custos elevados, estas medidas poderão assegurar uma significativa mudança da experiência de internamento pela criança e sua família. (ESTEVES et al, 2014, p. 701).

Outras sugestões são encontradas na literatura, entre as quais ressalta-se: a utilização de batas e jalecos coloridos ou com motivos infantis; decoração infantil no ambiente ou, ainda, o acesso livre da criança a objetos adequados aos seus gostos, interesses e nível de desenvolvimento.

Os recursos materiais existentes na brinquedoteca devem, portanto, atender às necessidades de lazer e escolarização de crianças e adolescentes em período de internação, de modo que seus familiares também possam desfrutar de alguns momentos de descontração durante o acompanhamento.

A subcategoria brinquedoteca como setor de humanização refere-se ao que está definido na Política Nacional de Humanização (BRASIL, 2013) que pressupõe inclusão das diferenças nos processos de gestão e de cuidado. Tais mudanças são construídas não por uma pessoa ou grupo isolado, mas de forma coletiva e compartilhada de forma a estimular a produção de novos modos de cuidar e novas formas de organizar o trabalho. Nesse sentido, algumas falas se mostraram relativas a essa preocupação:

Sobre as crianças, as que têm condições físicas se dirigem até a brinquedoteca e lá, um ambiente saudável, lúdico e alegre, elas reportam à sua vida cotidiana fora do hospital, trazem à memória situações de aprendizagem e lazer que tentam reviver. Esta prática contribui para o resultado favorável do tratamento e do restabelecimento da saúde das crianças. (E7 - UR174).

Eu vejo que as crianças ficam muito tempo dentro do hospital., uma delas, inclusive, me pediu um papel e lápis para ela rabiscar, desenhar, pintar. E então fiquei pensando que ali deveria mesmo ter alguma coisa que ajudasse no desenvolvesse dessas crianças enquanto elas estão ali dentro do hospital. (E5 - UR99). 
A brinquedoteca como setor de humanização é o espaço do hospital em que é possível o distanciamento temporário de uma rotina estressante dos procedimentos médicos: doloridos e que remetem a uma simbologia de medo e dor. Nesse sentido,

Esteves et al (2014, p. 699) salientam a importância da humanização hospitalar, dando ênfase à reflexão e sugere medidas em relação à melhoria dos cuidados ao paciente pediátrico; melhoria dos processos de comunicação interpessoal entre os diferentes agentes hospitalares; melhoria das condições de trabalho dos profissionais de saúde, e da melhoria da qualidade da 'atmosfera' hospitalar.

São muitos os argumentos que justificam a afirmação de que a brinquedoteca se configura como setor de humanização. Neste ambiente o atendimento pode ser individual e coletivo, tendo facilitada também a atenção individualizada neste ambiente, já que há profissionais para ouvi-los, dar atenção, o que colabora muito para a recuperação do quadro de saúde dos mesmos.

A subcategoria infraestrutura acadêmica refere-se a documentar todas as informações sobre estudantes/pacientes, como: registro de matrícula na escola regular, histórico escolar (quando a escola de origem disponibiliza para o hospital), atividades, avaliações e registro da rotina com o aluno-paciente.

Quando recebo uma criança ou adolescente, ela(e) já passou pela triagem médica e já tem em seu prontuário informações sobre sua doença, medicamentos que está tomando, dieta, enfim, todas as informações médicas que vou precisar para trabalhar com ele. Por isso, estou sempre em contato com a equipe médica para saber qual a evolução do quadro de saúde da criança. (E1 - UR20).

[...] seria interessante ter tudo documentado ... acho interessante isso ser uma regra já estabelecida! A gente ter esse acesso e pode-se chegar e ter as informações registradas. Dou um exemplo: agora são treze horas, uma criança hoje não se sentiu bem, precisou ser medicada com tal e tal medicamento. Antes de eu começar a atuar de fato, preciso saber qual é o histórico, o que essa criança tem. Por que ela está internada, qual é essa gravidade, o que isso interfere em meu trabalho, Entre outras coisas. Eu preciso conseguir desenvolver meu trabalho melhor. (E6 - UR21). 
De acordo com as entrevistas, tal documentação ajudaria a equipe de saúde com informações sobre o comportamento do aluno-paciente durante sua permanência na classe hospitalar. $\mathrm{O}$ professor deve ter o acesso aos prontuários dos usuários das ações e serviços de saúde sob atendimento pedagógico, seja para obter informações, seja para prestá-las do ponto de vista de sua intervenção e avaliação educacional.

Também está previsto que ambientes devem ser projetados com o propósito de favorecer o desenvolvimento e a construção do conhecimento para crianças: uma sala para desenvolvimento das atividades pedagógicas com mobiliário adequado e uma bancada com pia são exigências mínimas; instalações sanitárias próprias e adaptadas e espaço ao ar livre adequado para atividades físicas e ludo-pedagógicas.

Da mesma forma, a disponibilidade desses recursos propicia condições mínimas para que o educando mantenha contato com colegas e professores de sua escola, quando for o caso.

A quarta subcategoria participação da Família também se ampara no que é previsto no Política Nacional de Humanização (BRASIL, 2013): acolher e reconhecer o que o outro traz como legítima e singular necessidade de saúde e que o processo de inclusão deve prever a construção de relações de confiança, compromisso e vínculo entre as equipes/serviços, trabalhador/equipes e usuário com sua rede socioafetiva. Vejamos as falas da entrevista:

[...]A K. é que está há mais tempo aqui e a gente percebe que quando tem incentivo da mãe - a mãe é que está mais em contato com a criança, com o jovem, que está mais presente, e quando tem incentivo, quando tem uma cobrança, quando a mãe está ali, bem presente - a evolução da criança é outra. (E3 -UR89).

Aqui a classe hospitalar dá apoio muito grande para a família. Muitas vezes os familiares vêm buscar nossa ajuda no sentido de melhor entender a situação do internado, e os acompanhamos na conversa com o médico. Se a gente percebe que a mãe está aflita a gente fala com a psicóloga. Tem pessoas muito carentes, e às vezes elas não sabem como chegar, como fazer uma pergunta. (E4 - UR93).

Dahdah et al (2013) apontam a necessidade de se fazer adaptações no ambiente hospitalar, principalmente para o 
atendimento de crianças e adolescentes internados, além de assegurar-lhes atenção pedagógica. De acordo com a autora, há

uma mobilização dos profissionais de saúde sob as diretrizes de humanização da assistência, a facilitação do acesso de familiares ao cuidado de seus parentes no ambiente hospitalar, entendendo que a permanência da família como colaboradora facilita o processo de recuperação da saúde para o estudante/paciente internado. (p. 400).

O núcleo voltado a direcionar a formação do pedagogo para atuar em classe, leito e brinquedoteca hospitalares mostrou a percepção dos pedagogos em relação aos aspectos relevantes que envolvem o atendimento educacional no hospital. Como continuidade, apresenta-se a seguir o segundo núcleo direcionador que analisou as "Sugestões para o aprimoramento das práticas pedagógicas na classe hospitalar, leito e brinquedoteca”, do qual emergiram duas categorias e oito subcategorias.

Quadro 2 - Categorias e subcategorias a partir do segundo núcleo direcionador "Sugestões para o aprimoramento das práticas pedagógicas na classe hospitalar, leito e brinquedoteca”.

\begin{tabular}{|l|l|}
\hline \multicolumn{1}{|c|}{ CATEGORIAS } & \multicolumn{1}{c|}{ SUBCATEGORIAS } \\
\hline $\begin{array}{l}\text { 1 - Formação pedagógica espe- } \\
\text { cífica na Saúde }\end{array}$ & $\begin{array}{l}\text { 1a. Estágio em cenários hospitalares } \\
\text { 1b. Ampliação de olhares } \\
\text { 1c. Integralidade no cuidado } \\
\text { 1d. EEnfase na educação em saúde }\end{array}$ \\
\hline $\begin{array}{l}\text { 2- Processos ensino e aprendi- } \\
\text { zagem em contexto hospitalar }\end{array}$ & $\begin{array}{l}\text { 2a. Recursos didáticos } \\
\text { 2b. Recursos avaliativos } \\
\text { 2c. Humanização do ambiente } \\
\text { 2d. Planejamento educacional }\end{array}$ \\
\hline
\end{tabular}

Fonte: dados da pesquisa dos autores (2016).

A primeira categoria do segundo núcleo direcionado foi a “Formação pedagógica específica na saúde”, e dela emergiram quatro subcategorias. 
Os estágios em cenários hospitalares se mostram como contexto em que crianças e adolescentes que se encontram internadas necessitam de atenção peculiar, se comparada ao cenário escolar. Para garantir a continuidade de escolarização, respeitando todas as condições de saúde dos estudantes/pacientes, faz-se importante recuperar os excertos das entrevistas:

Não havendo algo específico relacionado à Pedagogia Hospitalar, acredito, ao menos, que o estágio deveria ser obrigatório também em ambiente hospitalar. (E1 - UR2).

[...] efeitos negativos do impacto da doença e do ambiente do hospital. Ninguém gosta de ficar internado. É uma quebra total de sua rotina com a família, amigos, escola, entender este processo é essencial. (E1- UR24).

Nos cursos de Pedagogia, o estágio é uma etapa do processo formativo obrigatório. A Resolução $n^{0} 1$, de 2015, prevê "quatrocentas horas dedicadas ao estágio supervisionado, na área de formação e atuação na educação básica, contemplando também outras áreas específicas, se for o caso, conforme o projeto de curso da instituição". (BRASIL, 2015, p.11).

Neste sentido, corroboramos a representação do entrevistado de que, a depender das propostas e projetos pedagógicos de cada curso e das instituições de ensino superior, o estágio nesse locus deveria ser incentivado.

A subcategoria ampliação de olhares, em que docentes e profissionais da saúde nos hospitais devem procurar formas, estratégias pedagógicas que estimulem e alegrem as crianças e adolescentes durante os encontros para as atividades escolares e seus responsáveis. O "olhar ampliado" é discutido na literatura e, também, uma sugestão para aprimoramento das práticas dos profissionais de educação.

O pedagogo hospitalar vai transpor essa parede e revelar para essas crianças e adolescentes que não são piores e nem melhores do que os outros, mas que são iguais a qualquer outra pessoa, estimulando assim, a autoestima dessas crianças. (E1 - UR6). 
[...] efeitos negativos do impacto da doença e do ambiente do hospital.

Ninguém gosta de ficar internado. É uma quebra total de sua rotina com a família, amigos, escola... (E1 - UR24).

Amparados em Dahdah et al (2013), corroboramos sua discussão de que o aluno, privado da possibilidade de desenvolver ações em prol de seu autocuidado e de compartilhar sentimentos de medo e de angústia em relação ao doente com os outros membros da família, principalmente nos casos em que esse se encontra em estado crítico de vida, demanda de trabalhadores da saúde lidar com tais situações.

A subcategoria integralidade no cuidado remete a ações integradoras concomitantes ao atendimento individualizado. No contexto da educação em saúde, a ação é evidenciada quando Ferreira et al. (2014) afirmam que a educação deve oportunizar reflexões e ações que possibilitem aprendizado consciente, sem a intenção de controlar suas vidas. Nesse sentido, a educação em saúde possibilita encontros entre profissionais e usuários do serviço de saúde, num diálogo e a troca de experiências.

$[Q]$ uando a gente percebe um problema emocional ali pode chamar a psicóloga pra conversar e dizer que a mãe apresentou determinado problema pra nós, ou quando a criança nos relata alguma coisa e demonstra que está angustiada. Ela não consegue dizer diretamente, pode ser até um caso de separação de pais. Ela já está num ambiente de hospital e às vezes não consegue fazer uma atividade com a gente porque também tem algo mais que não a deixa tranquila. A gente tem esse respaldo das outras profissões para melhor entender o caso. (E3 - UR89).

[S]e você não conseguir conciliar a parte psicológica, então não vai adiantar, você não vai conseguir porque, como a $\mathrm{K}$ falou, é difícil, é uma parte psicológica, pode ser até a morte de alguém! (E3 - UR13).

As emoções sentidas pelas crianças e adolescentes internados são muitas, e tanto pedagogos como professores hospitalares necessitam desse "olhar" diferenciado, como já destacado neste trabalho durante análise das falas dos entrevistados. 
Oliveira e Silvestro (2015) discutem os efeitos biopsicossociais envolvidos nesse processo educativo, pois o aprendente não pode ser visto apenas pela sua "doença", mas por diversos fatores envolvidos, já que, mesmo em cenário tão específico, o desenvolvimento permanece ativo. Nesse sentido, a atenção integral durante o período de internação requer envolvimento, participação de pedagogos, professores, família, equipe de saúde, escola em busca de ações que minimizem os impactos negativos gerados pela internação, como a reintegração social, quando estes retornam para seus lares, escola e comunidade em que vivem. Entender o estudante/paciente como um ser bio-psico-sócio-cultural, conceito recorrente na promoção da saúde, possibilita a integração dos profissionais e a otimização do tratamento.

Amparados em Farago e Silva (2014), reconhecemos que muitas vivências são interrompidas pelo período de internação, sejam sociais, cognitivas, experienciais podendo, a experiência escolar no hospital, possibilitar que o aluno permaneça em contato com elementos essenciais para a vida em sociedade. Nesse sentido, o pedagogo e professor hospitalares colaboram na mediação entre criança/adolescente internados e a escola, em parceria com a equipe de saúde e família, contribuindo para que o retorno dos alunos/pacientes à escola regular e ao convívio social seja menos doloroso.

A subcategoria ênfase na educação em saúde se refere, predominantemente, a orientações sobre educação em saúde são importantes. Também, o fato de que durante sua permanência no hospital deve sempre recorrer à equipe de saúde em casos que verifique a necessidade de orientação.

[C]onversei com a chefe de enfermagem do setor antes de entrar! Ela me atendeu superbem, me explicou muitas coisas, até questões da higienização das mãos e materiais, que é uma coisa básica! (E4 - UR23).

O álcool usamos para diminuir o risco de contaminação. Então, lavamos as mãos e usamos o álcool gel para minimizar o risco de contaminação. (E7 - UR27). 
Corroboramos Ferreira et al. (2014, p. 372), que afirmam que

“as práticas de saúde decorrem de experiências contínuas de ensino e aprendizagem, e acabam influenciando as decisões a serem tomadas, podendo contribuir para diminuir, manter ou elevar o seu nível de saúde".

Farago e Silva et al (2014, p. 180) também reforçam que tais cuidados são imprescindíveis, a exemplo do que acontece nos setores que atendem moléstias infecciosas, em que os brinquedos utilizados nas atividades lúdicas devem ser descartados após seu uso.

A segunda categoria do segundo núcleo direcionador foi "Processos de ensino e aprendizagem em contexto hospitalar", e desta emergiram cinco subcategorias. A primeira, recursos didáticos, diz respeito ao que um dos entrevistados chamou de "diversas formas de brincadeiras para ensinar" e esclareceu que há intencionalidade por parte do pedagogo na promoção de brincadeiras e em ambientes prazerosos de ensino e aprendizagem.

Quando falo lazer, quero dizer sobre o lúdico em aulas, utilizando das diversas formas de brincadeiras para ensinar, aliviando também a pressão emocional que o adoecido sofre por estar em um ambiente hostil. (E1 - UR3).

[...] as atividades lúdicas elaboradas e promovidas pelo pedagogo são de extrema importância para amenizar, reestabelecer e reintegrar o cliente ao meio em que vive. (E2 - UR7).

Sobre o brincar no contexto hospitalar, Sousa et al. (2015) discutem o comprometimento do desenvolvimento da criança decorrente da hospitalização e quebra de sua rotina interacionais e da necessidade de adaptação à nova realidade da internação, impactando em aspectos como seu desenvolvimento físico, emocional e intelectual.

As atividades lúdicas no contexto hospitalar colaboram no alívio da pressão causada pela permanência prolongada no hospital, já que processos sociais são deixados de lado na internação. Para Silva, et al. (2015), o lúdico é necessário como ferramenta que 
promove bem estar na criança, possibilitando desenvolver fantasias e sentimentos, que podem ser grandes aliados à sua recuperação.

Já para Torres et al (2015) a utilização da tecnologia não garante, em si, a qualidade, a pertinência e a relevância do processo pedagógico na sociedade do século XXI. O computador e a internet não substituem o professor, sendo ferramentas facilitadoras do processo educativo. Somam-se a esses, a segunda subcategoria: os recursos avaliativos, que basicamente se referem à avaliação da aprendizagem no contexto hospitalar. Nas escolas regulares, as avaliações são feitas a partir de aplicação de provas, já esgotadamente discutido por autores como Luckesi (2008) e Ferreira et al. (2014). Tais autores discutem não ser adequado que se restrinja à aplicação de técnica, mas também realize uma ação pedagógica que promova a articulação entre teoria e prática, permitindo o envolvimento do cidadão no processo de construção do cuidado à sua saúde. Os depoimentos coletados falam da importância da sondagem antes da avaliação do aprendizado da criança e do início das atividades docentes:

Ela tem que esse conhecimento da necessidade da criança ali porque a criança está debilitada, tem que fazer uma sondagem para saber o que cada criança necessita pra também não explorar a criança no desenvolvimento dela. (E5 - UR19).

[E]u já fiz prova de ciência, de história, de geografia de matemática,. Nossa, que nota eu tirei (...) você tirou sete ah!, você tirou cinco ah!, você tirou dez ah!. Você conseguiu tirar dez, parabéns, tirou dez, Matheus, em ciências. Isso mexeu com a autoestima de um jeito que me surpreendeu. (E6 - UR22).

Avaliação em contexto hospitalar demanda um olhar sensível às condições físicas e emocionais do estudante, que precisam ser consideradas, e mesmo que a, é necessária segundoSimões et al (2015).

A terceira subcategoria: humanização do ambiente, amparada em Simões et al (2015) que conceitua que o termo classe é segregador e coloca em risco entendimentos variados, 
propondo como mais apropriado o termo escola hospitalar, assim compreendida como um atendimento escolar que se desenvolve de forma humanizada no ambiente do hospital.

$[\mathrm{U}] \mathrm{m}$ ambiente saudável, lúdico e alegre reporta à vida cotidiana fora do hospital, traz à memória situações de aprendizagem e lazer que tentam reviver. (E7 - UR31).

O pedagogo que atua em hospital vai criar uma ponte entre essa rotina quebrada e a realidade que está sendo vivida, levando para o adoecido, além dos momentos de aula, as pessoas que são conhecidas de seu meio. (E1 - UR5).

Além de a terminologia 'classe' hospitalar não refletir a realidade prática desses espaços, já que não se trata de uma classe, separada do hospital, Simões et al (2015) apresentam que estudiosos consideram essa inadequação resolvida quando se reconhece que a enfermaria restringe o aluno a um espaço físico limitado que quase sempre é coletivo, impondo aos enfermos regras, procedimentos invasivos e incertezas que permeiam o imaginário sobre a saúde do aluno.

Esteves et al (2014) ressaltam que na última década, em níveis internacional e nacional, vários foram os investimentos no sentido de tentar definir o conceito de "humanização" no contexto da saúde, bem como em análises das vantagens dos projetos que visam a sua operacionalização. Os autores indicam ainda queo movimento de humanização pediátrica fomentou nos hospitais a possibilidade de a criança ter um acompanhante; o encorajamento dos pais para assumirem um papel ativo no cuidado da criança; o receber visitas; a dinamização de espaços lúdicos (por exemplo, ludotecas/brinquedotecas); a instalação de redes informáticas; ou a adequação da decoração ao público pediátrico. (2014, p. 698).

A partir dos relatos dos entrevistados verificou-se, na maioria deles, a busca pelo aperfeiçoamento e humanização dos ambientes em que ocorrem o atendimento pedagógico. 
$\mathrm{Na}$ quarta subcategoria planejamento educacional descreveremos situações que necessitam de planejamento na classe hospitalar, quais sejam: organização pessoal e ações que possam envolver conflitos e necessidade de busca de consensos". A falta de planejamento no exercício da profissão docente pode trazer sérias complicações tanto para quem ensina como para quem aprende.

Hoje o que muito se estimula são as atividades direcionadas e os planejamentos de curto prazo, diferenciados, para crianças no leito e crianças na brinquedoteca. Tem um cronograma de trabalho que precisa "casar" com a rotina do hospital. (E7 - UR28).

Possuímos toda uma estrutura acadêmica com registro das crianças, ficha de avaliação, planejamento, livro de registro de ocorrências, livro de leitos, carta de doação, pesquisa de satisfação da brinquedoteca junto aos pais - autorização de imagem, plano de atividades mensais e outros. (E7 - UR30).

A flexibilização do planejamento educacional em contexto hospitalar é importante pois antevê situações outras que podem vir a ocorrer. Quando o hospital oferece toda estrutura necessária para o atendimento de escolares em situação de internação, o planejamento fica ainda melhor, podendo o professor ter maior controle sobre as atividades previstas. Pode, igualmente, realizar as avaliações necessárias para possibilitar a continuidade dos estudos às crianças e adolescentes adoecidos e hospitalizados, diminuindo o distanciamento entre o hospital e a escola regular.

\section{CONSIDERAÇÕES FINAIS}

Em que pese uma formação insuficiente no curso de Pedagogia para a atuação nesse contexto hospitalar, vale ressaltar a importância da formação em serviço para dar maior consistência ao trabalho do pedagogo em diferentes áreas de atuação. Se capacitar para a diversidade nos cenários de atuação docente é importante para que as novas gerações tenham um outro grau de cidadania e tolerância. Ao analisar a percepção de pedagogos em 
relação à formação acadêmica e profissional para atuar em classe hospitalar, brinquedoteca e leitos hospitalares, ficam evidenciadas práticas e cuidados pedagógicos no cotidiano desse cenário de formação. A interdisciplinaridade também é fundamental na percepção dos professores, para quem esse trabalho deve considerar aspectos da saúde, políticas sociais, além da atividade docente de inclusão dos alunos internados e que necessitam da classe hospitalar não apenas para socializar, mas principalmente para ter seu direito à educação garantido.

\section{REFERÊNCIAS}

BATISTA, N.A.; BATISTA, S.H. (organizadores). Docência em saúde: temas e experiências. $2^{\circ}$ ed. rev. e ampliação. - São Paulo: Senac, 2014.

BAUMAN, Z. Globalização: as consequências humanas. Rio de Janeiro: Jorge Zahar, 2000.

BRASIL. Ministério da Educação. Classe hospitalar e atendimento pedagógico domiciliar: estratégias e orientações. / Secretaria de Educação Especial. - Brasília: MEC ; SEESP, 2002.

BRASIL. Classe hospitalar e atendimento pedagógico domiciliar: estratégias e orientações. Secretaria de Educação Especial. Brasília: MEC; SEESP, 2002.

BRASIL. Ministério da Saúde. SUS - Política Nacional de Humanização, 2013.

BRASIL. Senado Federal. Constituição da República Federativa do Brasil. Brasília, 2008.

BEHRENS, M.A. O paradigma emergente e a prática pedagógica. 4 ed. Petrópolis: Vozes, 2011.

COLLET, N.; HOLANDA, E.R. As dificuldades da Escolarização da Criança com Doença Crônica no Contexto Hospitalar. Rev. Esc. Enferm. USP. 45(2):381-9, 2011

COSTA, A.V.L.C.; MICAELY, T.J.; CARVALHO, M.J.C. de. O Brinquedista: um técnico em brinquedotecas na clínica de psicologia. Ideias \& Inovação. V. 3, N.1, p. 67-74, 2016. 
CRUZ, G.C.; ARAUJO, A.S. A Docência no Contexto Hospitalar: uma prática possível e necessária. Rev. Ed. Popular, Uberlândia, v. 13, n. 2, p. 25-35, jul/ dez. 2014.

DAHDAH, D.F.; CARVALHO, A.M.P.; DELSIMC, J.C.; GOMES, B.R.; MIGUEL, V.S. de. GRUPO DE FAMILIARES ACOMPANHANTES DE PACIENTES HOSPITALIZADOS: estratégia de intervenção da Terapia Ocupacional em um hospital geral. Caderno de Terapia Ocupacional. UFSCar, São Carlos, v. 21, n. 2, p. 399-404, 2013.

CONFERÊNCIA MUNDIAL DE EDUCAÇÃO ESPECIAL. Declaração de Salamanca. Sobre Princípios, Políticas e Práticas na Área das Necessidades Educativas Especiais. 1994. Disponível em: http://portal.mec.gov.br/ seesp/ arquivos/pdf/salamanca.pdf. - acesso em agosto de 2020.

ESTEVES, C.H.; ANTUNES, C.; CAIRES, S. Humanization in a Pediatric Context: the role of clowns in improving the environment experienced by hospitalized children. Interface. 18(51):697-708, 2014.

FARAGO, A.C.; SILVA, R. da. Pedagogia Hospitalar: a atuação do pedagogo em espaços não-formais de educação. Cadernos de Educação, 1 (1): 165 $185,2014$.

FERREIRA, V. F. et al. [Artigo]. Educação em Saúde e Cidadania: revisão integrativa. Trab . Educ. Saúde, Rio de Janeiro, v. 12 n. 2, p. 363- 378, 2014. Disponível em: http://www.scielo.br/pdf/tes/v12n2/a09v12n2.pdf. Acesso em: 05/02/2021.

FREIRE, P. Pedagogia da Autonomia: saberes necessários à prática educativa/ Paulo Freire - São Paulo: Paz e Terra, 15º edição, 1996.

LOSS, A. S. [Artigo]. A Autoformação no Processo Educativo e Formativo Profissional da Educação. $37^{\mathrm{a}}$ Reunião Nacional da ANPEd - UFSC - Florianópolis 2015.

LUCKESI, C. C. Avaliação da Aprendizagem Escolar: estudos e preposições. $19^{\circ}$ Edição. São Paulo. Editora Cortez, 2008.

MINAYO, M.C.S.; DESLANDES, R.G.; SUELY, F. (org.). Pesquisa Social: Teoria, método e criatividade. 29. Ed. Petrópolis; RJ: Vozes, 2010.

MORAES, R. Análise de conteúdo. Revista Educação, Porto Alegre, v. 22, n. 37, p. 7-32, 1999. 
OliveirA, A. M. M.; SILVESTRO, V. S. O Impacto Emocional Sfrido pelo Escolar em Processo de Hospitalização. Akrópolis Umuarama, v. 23, n. 2, p. 15-27, jan./jun. 2015.

RODRIGUES, J. M.C. Classes Hospitalares: O Espaço Pedagógico nas Unidades de Saúde. Rio de Janeiro: Wak, 2012.

SANTOS, M.O.; PEREIRA, T.S.; BARRETO, M.O. Trabalho Pedagógico-Educacional em Classe Hospitalar: Um estudo de caso. Cairu em Revista. Ano 02, n 02, p. 158-173, 2013.

SIMÕES, V. A. P.; SILVA, D.; TREVISAN. L.; MARQUES, M.; HIPOLITO, P. S. A importância da pedagogia: educação e aprendizagem no contexto hospitalar. EDUCERE, Umuarama, v. 15, n. 1, p. 47-56, 2015.

SOUSA, L. C. et al. The act of playing within the hospital context in the vision of the accompanying persons of the hospitalised children. Revista Brasileira: Crescimento desenvolvimento humano, São Paulo, v.25, n.1, p.41-49, 2015.

TORRES, P.T.; BEHRENS, M.; MATOS, E.M. Prática pedagógica numa visão complexa na educação presencial e a distância: os 'REAS' como recurso para pesquisar, ensinar e aprender. Rev. Diálogo Educ., Curitiba, v. 15, n. 45, p. 443-471, 2015.

ZOMBINI, E.V. et al. Classe hospitalar: a articulação da saúde e educação como expressão da política de humanização do SUS. Trabalho, Educação e Saúde, Rio de Janeiro, v. 10, n. 1, p. 71-86, 2012. 